\title{
PEMBUATAN SITUS WEB PUSAT KEBUDAYAAN BETAWI DENGAN MENGGUNAKAN PHP DAN MYSQL
}

\author{
Bay Haqi $^{1}$, Junita Yosephine Sinurat ${ }^{2}$, Mima Nizma ${ }^{3}$ \\ Program Studi Informatika,Universitas Indraprasta PGRI \\ bayhaqiunindra@gmail.com¹, junitasinurat@gmail.com², nizma_funky@yahoo.com³
}

\begin{abstract}
Abstrak
World Wide Web saat ini berkembang dengan pesat pada berbagai bidang kehidupan manusia.Pada mulanya perkembangan World Wide Web hanya bersifat pertukaran informasi yang statis artinya komunikasi yang terjadi antara penerima informasi dengan penyedia informasi hanya bersifat satu arah saja. Penerima hanya mendapatkan informasi dari penyedia informasi dan tidak dapat berinteraksi dengan penyedia tersebut. Biasanya sistem seperti ini disebut web statis. Situs pusat kebudayaan Betawi juga berusaha mengembankan diri dengan membuat web yang lebih interaktif dan menarik sehingga diharapkan banyak masyarakat yang ingin mengetahui kebudayaan Betawi dapat dengan mudah mendapatkan informasinya. Situs ini juga berusaha mendokumentasikan secara digital sehingga kebudayaan Betawi dapat dikenal dan diketahui oleh masyarakat luas serta tidak hilang ditelan perkembangan zaman yang semakin cepat.
\end{abstract}

Kata kunci :Budaya, Betawidan Web

\section{Abstract}

The World Wide Web is rapidly developing in many aspects of human life. At first, the development of the World Wide Web is only a static information exchange in which the recipient and provider of informationonlyestablish one-way communication. The recipient only gets information from the information providerswithoutinteracting with them. This kind of system is usually calledthe static web. Further, the Betawi cultural center site is trying to develop itself by creating the more interactive and interesting web that can help many people who want to know Betawi culture easily get information. This site also tries to make digital documentation so that the Betawi culture can be known by the public and be saved from extinction due to rapid development of the era.

Keywords: Culture, Betawi and Web

\section{PENDAHULUAN}

Suku Betawi berasal dari hasil akulturasi antar-etnis dan bangsa di masa lalu. Secara biologis, mereka yang mengaku sebagai orang Betawi adalah keturunan kaum berdarah campuran aneka suku dan bangsa yang didatangkan oleh Belanda ke Batavia.Budaya betawi memiliki beraneka ragam kebudayaan-kebudayaan yang menciri-khaskan ke-eksistensian mereka di Indonesia. Dalam bidang kesenian, misalnya, orang Betawi memiliki seni Gambang Kromong yang berasal dari seni musik Tionghoa, tetapi juga ada Rebana yang berakar pada tradisi musik Arab, Keroncong Tugu dengan latar belakang Portugis-Arab, dan Tanjidor yang berlatarbelakang ke-Belanda-an.
Pada masa kini kebudayaan Betawi semakin tergerus oleh arus globalisasi. Karena globalisasi diusung oleh negaranegara maju (Barat) yang memiliki budaya berbeda dengan negara-negara berkembang, maka nilai-nilai Barat bisa menjadi ancaman bagi kelestarian budaya lokal di negara-negara berkembang, termasuk Indonesia. Pembuatan sebuah situs web tidak bisa terlepas dengan bahasa pemrograman, dalam hal ini penulis menggunakan PHP sebagai bahasa scripting dan MySQL sebagai database server. PHP dan MySQL adalahpasangan bahasa scripting dan database server yang banyak diminati akhir-akhir ini. Ketangguhan, jaminan keamanan yang tinggi, dan kemudahan mempelajari 
membuat keduanya banyak dipilih untuk digunakan.

\section{A. Kebudayaan}

Kebudayaan menurut definisi antropologi adalah seluruh sistem gagasan dan rasa, tindakan, serta karya yang dihasilkan manusia dalam kehidupan bermasyarakat, yang dijadikan miliknya dengan belajar [1].Menurut Geertz budaya terdiri dari struktur makna yang hadir secara sosial, tempat manusia saling berkomunikasi, tak terpisahkan dari wacana sosial yang bersifat simbolik [2].Budaya bersifat publik karena maknanya dan sistem maknalah yang menghasklkan budaya. Lebih lanjut Geertz memiliki asumsi bahwa budaya merupakan milik kolektif dari masyarakat dan budaya merupakan sekumpulan teks.

Definisi budaya oleh berbagai pengamat menunjukkan ambiguitas atau perbedaan penafsiran. Dalam kajian antropologi, umumnya budaya mengacu pada perilaku manusia. Salah satu unsur pengikat dari suatu komunitas, suatu etnis, atau bangsa adalah kebudayaan [3]. Adapun, jika mengacu pada konsep pokok budaya oleh Kroeber dan Kluckhohn akan kita dapatkan lebih dari seratus definisi budaya yang cukup gaduh [4].

\section{B. Konsep Dasar Sistem Informasi}

Di dalam mendefinisikan suatu sistem terdapat dua kelompok pendekatan, yang menekankan pada prosedurnya atau elemennya. Pendekatan yang lebih menekan pada prosedurnya dapat didefinisikan sebagai berikut: "suatu sistem adalah suatu jaringan kerja padaprosedurprosedur yang selaluberhubungan, berkumpul bersama-samauntuk melakukan kegiatan ataumenyelesaikan suatu sasaran tertentu'[5].

Sistem adalah sekumpulan elemen yang saling terkait atau terpadu yang dimaksudkan untuk mencapai suatu tujuan. Sebagai gambaran, jika dalam sebuah sistem terdapat eleman yang tidak memberikan manfaat dalam mencapai tujuan yang sama, maka elemen tersebut dapat dipastikan bukanlah bagian dari sistem.

Ada beberapa elemen yang membentuk sebuah sistem,yaitu :

a. Tujuan,

b. Masukan,

c. Keluaran,

d. Proses,

e. Mekanisme pengendalian, dan

f. Umpan balik.

a. PHP

PHP atau Hypertext Preprocessor pertama kali diperkenalkan oleh Rasmus Lerdorf pada tahun 1995 untuk keperluan dinamisasi Web Site pribadinya. PHP juga memenuhi kebutuhan akan bahasa scriptingserver side yang sederhana, kuat, dan memilikikonektivitas dengan beragam database server.

b. MySQL

MySQL merupakan database server yang berhubungan erat dengan PHP. MySQL adalah sistem manajemen basisdata relasi yang bersifat terbuka atau open source.

\section{METODE PENELITIAN}

Pembangunan web situsbudayaBetawi ini menggunakan model sekuensial linier. Sekuensial linier adalah sebuah pendekatan pengembangan perangkat lunak yang sistematik dan sekuensial. Model sekuensial linier melingkupi aktivitas seperti ditunjukkan pada Gambar 1:

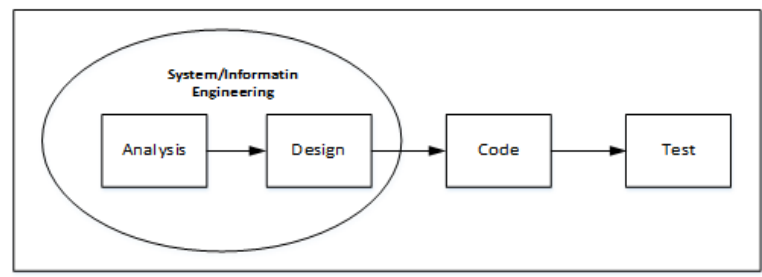

Gambar 1. Model Sequential Linier

System atau Information Enginnering merupakan bagian dari sistem yang terbesar dalam pengerjaan suatu aplikasi. 
Menetapkan berbagai kebutuhan semua elemen yang diperlukan sistem dan mengalokasikannya ke dalam pembuatan perangkat lunak.

Analisis merupakan tahap menganalisa halhal yang diperlukan dalam pelaksanaan pembuatan aplikasi perangkat lunak.

Design merupakan tahap dimana perangkat lunak secara aktual merupakan beberapa langkah proses yang berfokus pada empat buah atribut berbeda dari program yaitu struktur data, arsitektur perangkat lunak, representasi antarmuka dan detail prosedural (algoritma).

Coding merupakan tahap dimana hasil desain harus ditranslasikan ke dalam bentuk yang dimengerti oleh mesin dalam hal ini adalah bahasa pemrograman. Jika desain dilakukan dalam cara yang detail, maka pembuatan kode dapat di kerjakan secara mekanistik.

Testing adalah tahap pengujian program yang sudah di buat. Proses testing di fokuskan pada logika internal dari perangkat lunak, memastikan bahwa semua statement telah diuji dan pada eksternal fungsional. Test tingkah laku untuk error yang tidak tertangani dan memastikan bahwa pendefinisian masukan akan memberikan hasil yang aktual dan sesuai dengan hasil yang dibutuhkan.

\section{A. Analisis System}

Penulis menggunakan analisa Objeck Oriented Design dengan digram UML. Namun penulis hanya menggunakan dua diagram yaitu Use Case Diagram dan Class Diagram.

a. Use Case Diagram

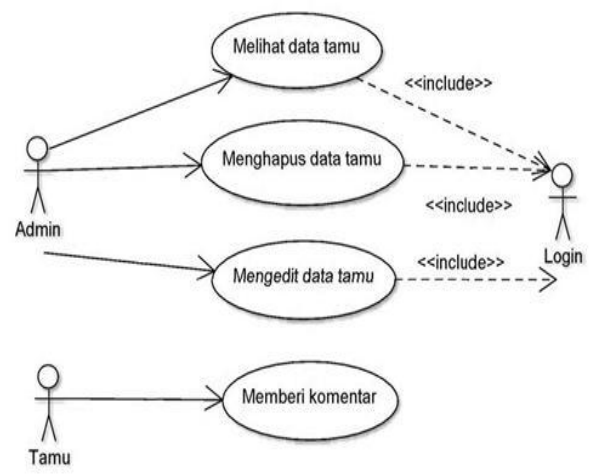

Gambar 2. Use Case Diagram

Dimana di situs yang dibangun ini terdiri dua user utama. Satu sebagai admin yang memiliki hak akses penuh dalam memanajemen web dan user sebagai tamu yang hanya memilik akses hanya untuk melihat situs.

b. Class Diagram

\begin{tabular}{|l|}
\hline \multicolumn{1}{|c|}{ komentar } \\
\hline no: Integer \\
nama : Varchar \\
email : varchar \\
HP : Varchar \\
komentar : longtext \\
\hline insert() \\
update() \\
delete()
\end{tabular}

\begin{tabular}{|l|}
\hline \multicolumn{1}{|c|}{ login } \\
\hline no: Integer \\
usn: varchar \\
pwd: varchar \\
\hline insert() \\
\hline
\end{tabular}

\section{Gambar 3. Class Diagram}

Dalam database situs ini hanya memiliki 2 table yaitu table komentar dan login. Dalam table komentar tersimpan semua komentar dari tamu. Dan dalam table login, table ini yang mengatur hak akses di situs yaitu sebagai admin atau sebagai tamu. Jika sebagai admin maka datanya akan tersimpan namun bila sebagai tamu data user tidak tersimpan di dalam situs/database.

Metode penelitian menjelaskan rancangan kegiatan, ruang lingkup atau objek, bahan dan alat utama, tempat, teknik pengumpulan data, dan teknik analisis penelitian. 


\section{HASIL DAN PEMBAHASAN}

Alamat website localhost/budaya.php menampilkan aneka ragam kebudayaan Betawi seperti sejarah, makanan, minuman, kesenian, dan upacara kebudayaan Betawi.

1. Halaman 'Home"

Halaman Home berisi tentang asal dan sejarah suku Betawi. Halaman website menampilkan pasangan abang \& none Jakarta yang menggunakan pakaian adat Betawi, gadis Betawi yang sedang menari, dan ikon kota Jakarta seperti Monas, Gereja Katedral, Masjid Istiqlal.

?
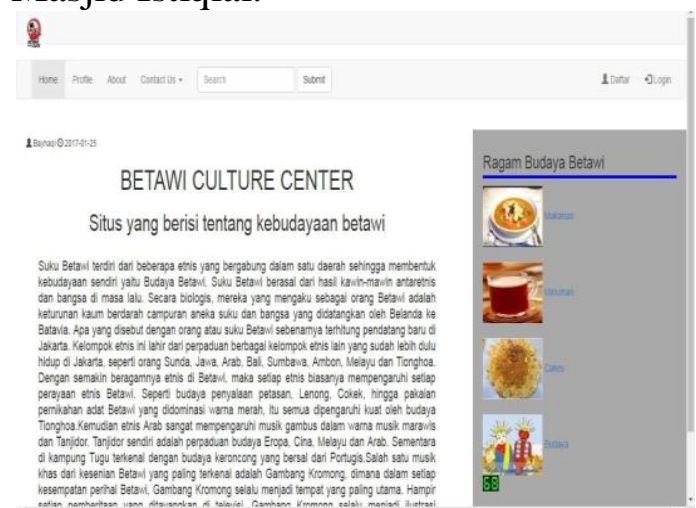

\section{Gambar 4. Sejarah Betawi}

2. Halaman Food

Halaman ini menampilkan makanan khas suku Betawi seperti nasi uduk. a

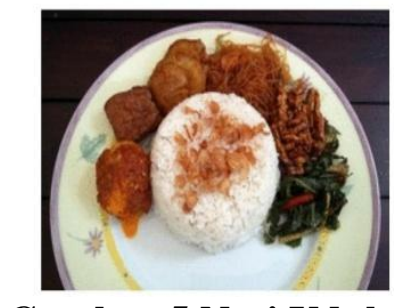

\section{Gambar 5.Nasi Uduk}

3. Halaman Drink

Halaman ini menampilkan minuman khas suku Betawi .

\section{里}
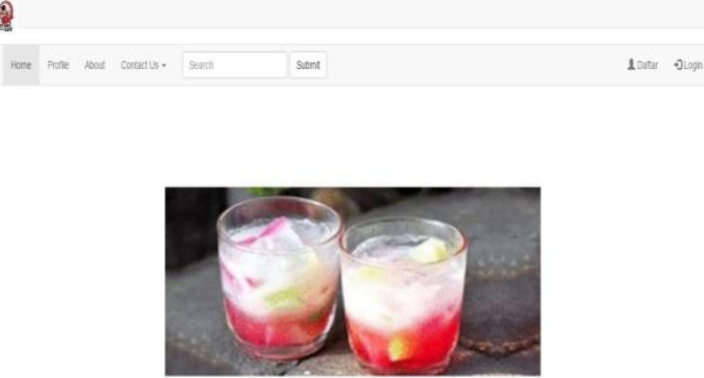

Gambar 6. Minuman khas betawi

4. Halaman Cakes

Halaman ini menampilkan penganan ringan atau jajanan pasar khas Betawi. 悉

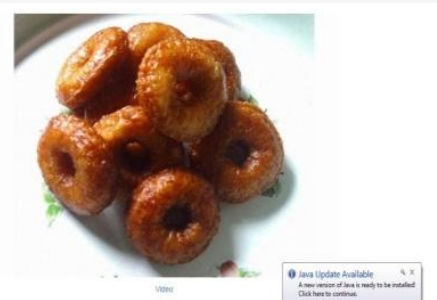

Gambar 7. Kue/ Jajanan Pasar

5. Halaman Culture

Halaman ini menampilkan kesenian dan upacara kebudayaan Betawi.

逢

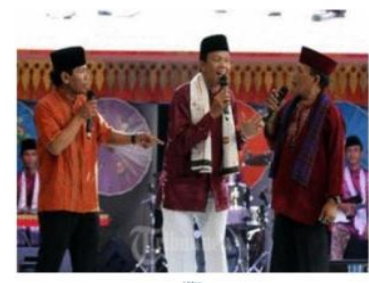

Gambar 8. Lenong Betawi

6. Halaman Comment

Halaman ini menampilkan jumlah pengunjung website. Pengunjung juga dapat memberikan kritik, saran dan pertanyaan tentang kebudayaan Betawi yang ditampilkan dalam halaman website dengan mengisi identitas dan komentar. 
\%
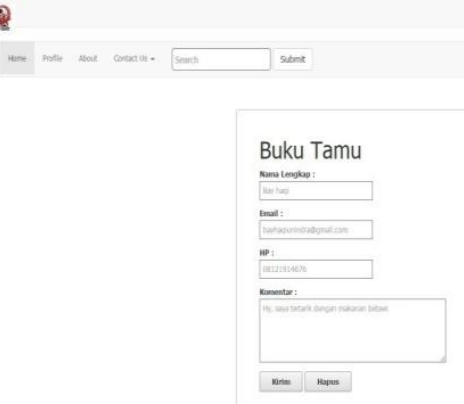

\section{Gambar 9.Buku Tamu}

7. Pengisian Identitas Pengunjung Halaman di bawah ini menampilkan jumlah pengunjung yang memberikan komentar. Dalam halaman ini juga pengelola website dapat menjawab pertanyaan atau menghapus komentar.

?

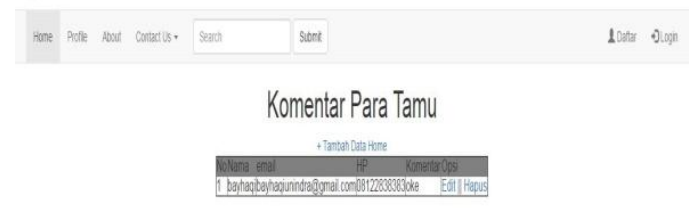

\section{Gambar 10.Jumlah Pengunjung yang Memberi Komentar}

8. Selain menampilkan gambar, dalam halaman website juga ditampilkan video tentang kebudayaan Betawi dan lainnya.

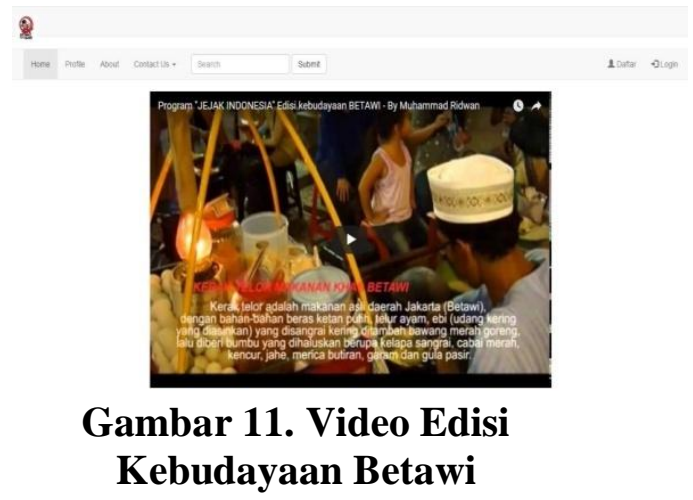

9. Halaman Login

Di halaman ini terdapat login untuk masuk sebagai admin. Jika tidak masuk login ini maka kita dianggap sebagai tamu yang hanya bias melihat dan memberi komnetar di buku tamu, namun tidak dapat melihat siapa saja yang member komentar.

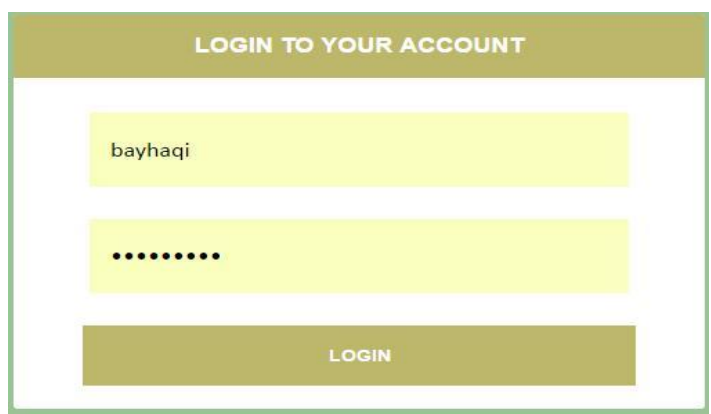

Gambar 12. Halaman login

\section{SIMPULAN}

Berdasarkan hasil pengolahan data dan analisis yang telah dilakukan dapat diambil beberapa kesimpulan seperti berikut:

1. Budaya Betawi memiliki beraneka ragam kebudayaan-kebudayaan yang menciri-khaskan ke-eksistensian mereka di Indonesia.

2. Kebudayaan Betawi merupakan bagian dari budaya nasional dan merupakan aset bangsa, maka keberadaanya perlu dijaga, diberdayakan, dibina, dilestarikan dan dikembangkan Budaya Betawi Perlu dijaga dan dikembangkan.

3. Website yang berisi tentang kebudayaan lokal memberikan banyak manfaat baik sebagai pengenalan kebudayaan Betawi bagi para pelajar khususnya dan masyarakat umumnya, tetapi juga sebagai media dalam melestarikan Kebudayaan Betawi.

\section{DAFTAR PUSTAKA}

[1] Koentjaraningrat. Pengantar Antropologi I. Cetakan ke-4. Jakarta: Rineka Cipta. 2011.

[2]. Hasan, S.S. Pengantar Cultural Studies: Sejarah, Pendekatan Konseptual, \& Isu Menuju Studi 
Budaya Kapitalisme Lanjut.

Jogjakarta: Ar-Ruzz Media.2011.

[3]. Tilaar, H.A.R. Mengindonesia Etnisitas dan Identitas Bangsa Indonesia. Jakarta: Rineka Cipta.2007.

[4]. Kaplan, D \& Robert. A.M. Teori Budaya. Cetakan ke-3. Yogyakarta: Pustaka Pelajar. 2002.

[5]. Jogiyanto, H.M.Analisis dan Desain Sistem Informasi.Yogyakarta: Andi. 1999. 